\title{
Primeira "ombudswoman" do Brasil: resgate de uma experiência pioneira
}

\author{
Marco Aurelio REIS ${ }^{1}$ \\ Cláudia THOMÉ ${ }^{2}$
}

\begin{abstract}
Resumo:
Um ano depois de o jornalista Caio Tulio Costa ter inaugurado, na Folha de S. Paulo, a primeira experiência oficial de crítica de mídia periódica e regular com base na função e espaço editorial de ombudsman, a jornalista Magda Almeida assumiria o mesmo papel no jornal $O$ Dia. Primeira brasileira a ter uma experiência de "ombudswoman", Magda atuou por 19 anos no diário carioca, a partir de 1990, e fez da atividade uma aproximação do veículo com seus leitores. O presente artigo reconstrói essa trajetória pioneira a partir de entrevista qualitativa em profundidade, com base na metodologia proposta por Bauer e Gaskell (2000) e Gil (1999). Com esse levantamento, busca contribuir para história do Jornalismo e para uma epistemologia da crítica de mídia periódica e regular na imprensa brasileira.
\end{abstract}

Palavras-chave: Ombudsman. Ombudswoman. Jornal O Dia.

\section{Brazil's first ombudswoman: rescuing a pioneering experience}

\begin{abstract}
:
A year after journalist Caio Tulio Costa inaugurated, in Folha de S. Paulo, the first official experience of regular and regular media criticism based on the ombudsman's role and editorial space, journalist Magda Almeida would assume the same role in the newspaper $O$ Dia. The first Brazilian woman to have an "ombudswoman" experience, Magda worked for 19 years in the carioca daily, from 1990, and made the activity an approximation of the vehicle with its readers. This paper reconstructs this pioneering trajectory from a qualitative in-depth interview based on the methodology proposed by Bauer and Gaskell (2000) and Gil (1999). With this survey, it seeks to contribute to the history of journalism and to an epistemology of periodic and regular media criticism in the Brazilian press.
\end{abstract}

Keywords: Ombudsman. Ombudswoman. O Dia journal.

\section{Primera "ombudswoman" en Brasil: rescatando una experiencia pionera}

\section{Resumen:}

Un año después de que el periodista Caio Tulio Costa inaugurara, en el periódico Folha de S. Paulo, la primera experiencia periódica de crítica periodística basada en la función editorial y el espacio del ombudsman, la periodista Magda Almeida asumiría el mismo papel en el periódico O Dia do Rio de Janeiro. Primera brasileña en tener experiencia en el papel de "ombudswoman", Magda ha trabajado

1 Doutor em Ciência da Literatura pela Universidade Federal do Rio de Janeiro (UFRJ), professor e bolsista de Pesquisa e Produtividade da Universidade Estácio de Sá (Unesa-RJ). E-mail: marco.reis@estacio.br

2 Doutora em Ciência da Literatura pela Universidade Federal do Rio de Janeiro (UFRJ), professora adjunta da Faculdade de Comunicação e do Programa de Pós-Graduação em Comunicação da Universidade Federal de Juiz de Fora (Facom/PPGCOM/UFJF).E-mail: cthomereis@gmail.com 
desde 1990 y durante 19 años en el periódico de la ciudad de Río de Janeiro y transformó la actividad en una forma de acercar a los lectores del periódico de Río de Janeiro. Este artículo reconstruye esta trayectoria pionera basada en una entrevista cualitativa en profundidad, utilizando la metodología propuesta por Bauer y Gaskell (2000) y Gil (1999). Con esta investigación, el trabajo busca contribuir a estudios sobre la historia del periodismo y la epistemología de la crítica periodística periódica y regular en la prensa brasileña.

Palabras clave: Ombudsman. Ombudswoman. periódico O Dia.

\section{Introdução}

A expressão sueca ombudsman (homem que representa) identifica uma espécie de ouvidor-geral. Surgida na Suécia em 1713, entrou para constituição daquele país em 1809, um ano depois de o Brasil ter, enfim, seu primeiro jornal impresso publicado. No acalorado ano de 1967, nos Estados Unidos, o termo seria retomado pela imprensa daquele país para tratar desse jornalista representante dos leitores frente à linha editorial e aos jornalistas da publicação onde atua. Com papel de criticar regulamente a mídia periódica, passaria a ter espaço cativo nas páginas do jornal que o contratara (COSTA, 2006).

As primeiras experiências nesse sentido são registradas nos periódicos CourierJournal, de Louisville, e The Washington Post, de Whashington, DC. Nas décadas seguintes, tal função começa a surgir na Europa, especificamente na Espanha, com o jornal El País e, na França, no tradicional Le Monde (COSTA, 2006). Na definição do professor Mário Mesquita, o ombudsman na imprensa forma "uma quarta instância, chamada a intervir a posteriori, relativamente às queixas dos 'consumidores' ou dos 'promotores', com vista a reexaminar, do ponto de vista ético, o processo de informação" (MESQUITA, 1998, p. 91).

É a nomeação de seu primeiro ombudsman pelo diário espanhol El País, então espelho editorial para Folha de S. Paulo, que teria levado o jornal paulistano a inaugurar, em 1986, um espaço na redação que ganhou uma placa com o nome da nova função. A novidade apareceu após uma reforma feita na redação que levou ar condicionado, carpetes e móveis novos para um espaço onde estavam toda a direção de redação e o editor da coluna política do jornal. A posição ficou sem ocupante por três anos, até que, em setembro de 1989, o jornalista Caio Tulio Costa foi nomeado para o cargo com mandato de um ano, então com a possibilidade de ser renovado por mais um ano (COSTA, 2006, p 15-16).

Meses depois, no primeiro semestre de 1990, a jornalista Magda Almeida, com 
vasta experiência profissional nos diários Jornal do Brasil, Estado de S. Paulo e Jornal da Tarde, assumiria a mesma função no jornal carioca $O$ Dia. Foi a primeira mulher a ocupar tal papel de ouvidoria na imprensa brasileira, em um jornal que buscava se qualificar e estreitar laços com seus leitores.

O presente artigo busca resgatar essa trajetória de Magda Almeida como ombudsman ou "ombudswoman". Para tanto, foi relevante entrevistar a jornalista com base na metodologia proposta por Bauer e Gaskell (2000) e Gil (1999). Com esse levantamento, o trabalho buscou impressões pessoais e detalhamento da rotina da profissional que marcaria a atividade no Brasil, de modo a contribuir para os estudos de história da comunicação e para uma epistemologia da crítica de mídia periódica e regular na imprensa brasileira.

\section{Magda, a "ombudswoman" de O Dia}

Em janeiro de 2018, quando a jornalista Flávia Lima passou a ser a sexta mulher a ocupar o cargo de ombudsman na Folha de S. Paulo, o jornal publicou uma nota defendendo que, como no caso de suas antecessoras, não a identificaria como "ombudswoman", uma vez que o termo ombudsman seria comum aos dois gêneros.

Ombudsman é palavra sueca - que significa representante do cidadão utilizada igualmente para os dois gêneros. Não teria sentido usar regra da língua inglesa. Tanto que, no caso de plural, a Folha usa ombudsmans e não ombudsmen. Nos EUA, há quem utilize ombudswoman ou até ombudsperson. (CURIOSIDADE... 2018, não paginado).

Ocorre, porém, que no jornal carioca $O$ Dia, na década de 1990, com uma redação então composta por jornalistas recém-formados e por jornalistas mais experientes notadamente oriundos do Jornal do Brasil, Magda Almeida era carinhosamente chamada de "ombudswoman", exatamente para sublinhar seu pioneirismo como primeira mulher no Brasil a assumir tal responsabilidade.

Como dito acima, Magda Almeida começou sua carreira no Jornal do Brasil, onde trabalhou de 1964 a 1974. Depois foi para o Jornal da Tarde e para o Estado de S. Paulo, onde permaneceu por 17 anos, em seguida foi para $O$ Dia, jornal no qual atuou como "ombudswoman" e, posteriormente, como presidente da Fundação Ary Carvalho, braço social, cultural e educacional do jornal carioca (ALMEIDA, 2006).

No $J B$, Magda conviveu com Clarice Lispector e Alberto Dines, entre outros grandes nomes da imprensa nacional. 
Imagine você entrando no elevador e dando de cara, quase todos os dias, com a Clarice Lispector. Não importa se sempre emburrada, olhar permanentemente pra baixo, nenhum sorriso e expressão sempre grave num rosto que espelhava uma alma com mais angústias do que poderia carregar. Era a Clarisseeee, já então um ícone. Não havia e-mail nem ela deixava suas crônicas na portaria. Subia na redação e entregava seus manuscritos, pessoalmente, às chefias. Que tal bater inesquecíveis papos pelos apertados corredores do velho prédio (da Avenida Brasil, 500), com Marina Colasanti e Affonso Romano de Sant'Anna? Onde mais e em que época você teria o privilégio de ter à sua volta os principais nomes da literatura brasileira te ensinando a escrever com estilo, graça e maestria, ainda que você mal tivesse o segundo grau? Ou entrar na redação e dar de cara com Pixinguinha rodeado de focas embasbacados, dando uma canja em seu clarinete?? E Chico? Marieta? Caetano? Tom Jobim? Vinicius? Toquinho? Otto Lara Resende? Paulo Mendes Campos? Rubem Braga, Nelson Cavaquinho, Cartola, Fernanda Montenegro, Madame Satã, só para citar alguns? Aquela redação do JB era uma permanente passarela cultural, onde desfilavam, como se em casa estivessem, os grandes nomes da música, da literatura e do teatro nacional (ALMEIDA, 2006, p. 50-51).

Durante o tempo em que ficou no $J B$, Magda teve como editor-chefe o jornalista Alberto Dines (1932-2018). Segundo ela, Dines foi seu mentor por todos os 12 anos em que ela passou lá, tanto na sede da Avenida Rio Branco quando na sede da Avenida Brasil, 500. De acordo com Magda, Alberto Dines, Carlos Lemos e José Silveira formaram a trinca de chefes que a ensinou a fazer jornal. Segundo Magda, Dines foi o primeiro ombudsman não formal na imprensa brasileira, uma vez que, de 1975 a 1980, assinava uma coluna dominical na Folha de S. Paulo chamada Jornal dos Jornais, onde exercia a crítica da mídia em geral e também do jornal onde trabalhava. Foi a partir de tal coluna que Dines teria idealizado seu "Observatório da Imprensa", programa de TV e de rádio e site com ares de um imenso ombudsman de todo o jornalismo praticado no Brasil.

\footnotetext{
Sem meias palavras, fazia questão de dizer. A coluna foi o embrião do que, mais tarde, faria o Caio Túlio. O sofrimento moral do Dines não foi menor do que o meu, até porque o dele tinha outros ingredientes que se somavam ao cargo em si. Mas aceitou o desafio. Embora, como uma vez me disse, ter "comido o pão que o diabo amassou", seguiu adiante, meio que aos trancos e barrancos. Machucou-se bastante, nunca deixou de enfatizar aos mais próximos. Um trabalho frustrante, como é, no Brasil, a função, mas, ao mesmo tempo, enriquecedor, porque nos permite enxergar a fera mais de perto (ALMEIDA, 2019) ${ }^{3}$.
}

De acordo com a jornalista, outra grande escola em sua carreira foi o grupo Estado de S. Paulo. "São Paulo é um Rio com banho de loja, portanto, escrevia-se com mais sofisticação e sobriedade, pelo menos no Estadão. O JT era miolo mais irreverente,

${ }^{3}$ ALMEIDA, Magda. Entrevista cedida a Marco Aurelio Reis, Rio de Janeiro, 23 out. 2019. 
mais solto, dava mais espaço para a criatividade”, conta (ALMEIDA, 2006, p. 52). De volta à imprensa carioca, em 1990, assumiu a responsabilidade de ser a primeira jornalista a ocupar o posto de ombudsman, inaugurando a função entre os jornais do Rio de Janeiro.

Era diferente de tudo o que já havia feito na vida. Achei que não iria sobreviver. Não só sobrevivi, como vivenciei uma das mais gratificantes experiências humanas, que aconselho a todos. Um longo e inesquecível aprendizado. Foi como se tivesse começado tudo de novo, num outro plano, fazendo um outro tipo de jornalismo, nem por isso menos importante. Nunca tinha visto o povo brasileiro tão de perto (ALMEIDA, 2006, p. 53).

O jornal $O$ Dia, onde Magda Almeida foi trabalhar, era bastante diferente daquele que ela conhecia quando atuava no Jornal do Brasil, 15 anos antes. Fundado em 5 de junho de 1951, O Dia, conforme consolida Reis (2015), foi idealizado por Antônio Chagas Freitas, que posteriormente seria empossado, de forma afinada ao regime militar, ${ }^{4}$ como governador do estado da Guanabara (de 1971 a 1975) e, mais tarde, novamente "eleito" de forma indireta para governar o estado do Rio de Janeiro (de 1979 a 1983). Chagas Freitas fundara o jornal para servir, na década de 1950, de palanque no Rio para o então governador de São Paulo Adhemar de Barros. Chagas Freitas era correligionário de Adhemar e dirigente de seu partido político, o Partido Social Progressista (PSP), no Rio. Os dois já eram sócios no jornal A Notícia, também do Rio de Janeiro (REIS, 2010).

Jornal compacto, de apenas oito páginas, O Dia alcançou grande circulação,
especialmente nos subúrbios da Central do Brasil, não só pelas notícias
policiais e o estilo populista, com apelos ao exótico, mas também por ser o
primeiro matutino a chegar às bancas, geralmente antes da meia-noite. O
primeiro secretário de $O$ Dia, jornalista Rui Santacruz Lima, adotava a
fórmula "cadáver, macumba e sexo" para escrever a manchete. "Se o
contínuo da redação não entende a manchete, ela não é boa", garantia
Santacruz, segundo conta Vilas-Boas Correia, primeiro jornalista contratado
pela Editora e Imprensa de Jornais e Revistas S.A., empresa editora de $O$
Dia. Repórter político, Vilas-Boas recebeu do secretário a tarefa de cobrir a
Câmara dos Deputados e o Senado de forma diferente da crônica política dos
matutinos de então. Surgiu assim a seção "Comandos Parlamentares", na qual
deputados e senadores, acompanhados do jornalista, realizavam visitas de

${ }^{4}$ É relevante reforçar que a ditadura foi instaurada no país a partir de um golpe civil-midiático-militar, conceito defendido pelo professor Juremir Machado da Silva, no livro 1964 - Golpe Midiático-CivilMilitar. O professor entende que o golpe contra o presidente João Goulart foi organizado e patrocinado por empresários, governadores de oposição ao presidente e militares. Os três grupos atuaram em sintonia. No grupo empresarial, além de latifundiários e exportadores, estavam donos de jornais e emissoras de rádio e $\mathrm{TV}$, bem como banqueiros.

$\mathrm{Na}$ década de 1970, as eleições eram indiretas, ou seja, levavam ao poder políticos afinados com o regime ditatorial, referendados pela maioria nas Assembleias Legislativas (Cf. BRANCO, 2002). 
fiscalização a órgãos do governo (LEAL; SANDRONI; BASTOS, 2009, não paginado).

Em 1983, seis anos antes da contratação de Magda Almeida como "ombudswoman", o jornal O Dia passou para o controle de Ary Carvalho, então proprietário do jornal Última Hora $(U H)$ do Rio e dono da empresa de sociedade anônima Ary Carvalho Editora, ou simplesmente Arca Editora S.A. Quatro anos depois, em 1987, Ary Carvalho vendeu o $U H$ e passou a se dedicar ao projeto de qualificação de $O$ Dia. As mudanças que Ary Carvalho empreenderia no jornal seriam graduais, e incluíram a atualização do seu logotipo, que de negativo passou a positivo, a publicação na primeira página de temas mais ecléticos e, posteriormente, a contratação da jornalista Magda Almeida para crítica diária do matutino.

\begin{abstract}
Em agosto de 1987, o jornalista Dácio Malta assumiu a direção do jornal, levando com ele Oriovaldo Perin e Eucimar de Oliveira. A nova equipe pretendia melhorar o padrão jornalístico, retirando o acessório e acrescentando informações e serviços para o leitor e sua família [...]. Em 1988, por sua "renovação gráfica buscando valorizar e ampliar o público leitor", O Dia recebeu o Prêmio Esso de melhor contribuição à imprensa, primeiro troféu de uma série que continuaria nos anos seguintes, destacando não só o trabalho profissional de jornalistas, mas também os da área de marketing, comercialização e circulação da empresa [...] Em 1991 a direção do jornal foi entregue a Marcos de Sá Correia e de sua equipe participaram Francisco (Xico) Vargas, Rui Xavier e Rute de Aquino. Em 1992, Eucimar de Oliveira substituiu Sá Correia [...] A edição comemorativa dos 40 anos de $\mathrm{O}$ Dia, publicada a 5 de junho de 1991, sua primeira edição em cores, já apresentava o desenho de uma reforma gráfica, realizada pelo designer Mário Garcia. A edição chegava às mãos dos leitores com 62 páginas, 20 das quais do suplemento especial comemorativo da data, e outras 24 de um caderno de classificados. Naquele mês a média diária da circulação era de 320 mil exemplares de segunda a sábado e 450 mil aos domingos (LEAL; SANDRONI; BASTOS, 2009, não paginado).
\end{abstract}

O empresário Ary Carvalho morreu no dia 4 de julho de 2003, ano em que a empresa de comunicação anunciou lucro de R\$ 14 milhões. O jornal passou a ser comandado por uma das três filhas do jornalista, a também jornalista Ariane Carvalho e, posteriormente, por outra das filhas, a empresária Ligia (Gigi) Carvalho. Três anos depois, em 2006, o jornal $O$ Dia buscou se posicionar como concorrente direto de $O$ Globo, ampliando o número de colunistas e abrindo maior espaço para as cartas dos leitores, ação que teve Magda Almeida à frente. A jornalista ficaria em O Dia até 2009.

\title{
A experiência como a primeira ouvidora de leitores de jornal no Brasil
}

Se os jornalistas são os "senhores da memória", como define Barbosa (2004), é 
necessário também entender a construção da memória do próprio jornalismo (BARBOSA, 2005) como campo de atuação profissional e também de conhecimento.

Construir uma história da imprensa é fazer o mesmo movimento que se produz para a "escrita da história", seja qual for o objeto empírico pesquisado. É perceber a história como um processo complexo, no qual estão engendradas relações sociais, culturais, falas e não ditos, interditos e silêncios que dizem muito mais do que qualquer forma de expressão, e que na maioria das vezes não foram deixados para o futuro (BARBOSA, 2005, p. 103).

Nesse sentido, entender as rotinas de produção nas redações dos jornais de tempos atrás faz parte dessa construção, para a história do jornalismo e para lançar luz sobre as condições em que as notícias foram selecionadas, debatidas, produzidas nas páginas dos jornais, nesse tensionamento gerado por negociações internas e disputas. "Na fixação da memória, estabelecem-se inúmeras disputas simbólicas, porque o relato da memória é uma construção do presente que negocia com o contexto social em que os sujeitos estão inseridos" (MUSSE; THOMÉ, 2015, p. 2).

No momento em que a primeira experiência de crítica diária de mídia no Brasil completa três décadas, é relevante resgatar como foi a atuação das jornalistas nessa função nas redações dos jornais, com destaque para a experiência daquela que inaugurou a presença feminina no cargo. Para o presente artigo, a jornalista Magda Almeida concedeu entrevista detalhando sua experiência como "ombudswoman". O relato da jornalista, décadas depois, vem carregado de lembranças sobre o desafio que representava, já naquela época, apontar os erros e desvios na produção de colegas em uma redação de jornal.

Segundo ela, o convite para ocupar o cargo em 1990 foi do economista Walter de Mattos Junior, então genro de Ary Carvalho, e que sete anos depois fundaria o jornal esportivo Lance.

\begin{abstract}
Mattos me conhecia apenas de nome, através de alguns editores com quem trabalhei nos tempos heroicos do Jornal do Brasil, décadas de 60,70 e 80 . Provavelmente, foram eles que me indicaram ao Ary Carvalho, quando este manifestou sua vontade de ter em seu jornal a figura do Ombudsman, seguindo o exemplo da Folha, que julgava o maior jornal do país e modelo de jornalismo moderno. Alguns editores sugeriram o meu nome, porque sabiam da minha eterna preocupação com o jornalismo que se fazia no país, de rara qualidade, demasiadamente amador para os paladares mais exigentes. Também alguns deles traziam da grande escola que foi o $J B$ aquela base indispensável para um jornalismo ao menos respeitável (ALMEIDA, 2019).
\end{abstract}

Magda Almeida inicialmente não aceitou o convite. Conhecia a então má fama 
de $O$ Dia. Ela lembra que, quando contou que recebera tal proposta entre os colegas do grupo Estado de S. Paulo, alguns colegas a procuraram para perguntar se havia enlouquecido. Alguns deram conselhos para ela não aceitar, argumentando que ela iria "passar de "cavalo a burro",", perguntando se ela não tinha consciência para onde estava indo e se tinha noção do que a esperava. Afirmaram inclusive que o jornal carioca nada tinha a ver com ela, até culturalmente, e que em nada melhoraria o extenso currículo da jornalista.

\begin{abstract}
Balancei. Mas a sucursal do Estadão (no Rio de Janeiro) não estavam em seus melhores momentos. Tudo ali também tinha ficado aquém das minhas potencialidades e sonhos, resultado de uma crise maior baseada na matriz em São Paulo, também passando por crises editoriais e de poder que não pareciam ter fim. Eu não queria aquilo pra mim. Já tinha passado dos 50 anos, sabia que, por vários motivos, nenhuma redação estaria receptiva a uma senhora de meia idade, cheia de exigências, e, pecado maior, sem militância política. Para onde iria àquela altura de minha vida pessoal e profissional, se resolvesse deixar a sucursal e colocar meu futuro profissional na pista? Muitas noites de sono perdidas depois, resolvi aceitar o desafio. Cheia de medo, não nego (ALMEIDA, 2019).
\end{abstract}

$\mathrm{Na}$ entrevista para o presente artigo, a jornalista por mais de uma vez classifica o jornal O Dia como uma "grande escola, profissional e de vida". Segundo ela, o empresário Walter de Mattos Junior foi “incansável” ao colocar à disposição dela tudo que precisasse para fazer o que ela "julgasse necessário". Magda Almeida ganhou uma sala, secretárias e liberdade de atuação.

\begin{abstract}
A primeira coisa que fiz foi pedir um tempo para conhecer mais de perto os jornais que, pioneiramente, mantinham esse cargo. Queria conhecer seus ocupantes, saber de suas rotinas, os desafios que enfrentavam, inevitáveis conflitos, como os resolviam, enfim, estavam conseguindo algum sucesso no sentido de melhor aproximar o jornal de seus leitores, conseguiam mudar velhos paradigmas que ainda atrasavam a modernidade editorial de seus jornais? Como ficaram as relações entre eles e seus colegas de redação pós Ombudsman? (ALMEIDA, 2019).
\end{abstract}

Magda Almeida começou sua pesquisa pelo jornalista pioneiro na função no Brasil, Caio Túlio Costa, da Folha de S. Paulo, então um "jornal modelo de alguns empresários". Segundo seu relato, a jornalista passou uma semana indo diariamente à sala de Caio Túlio, observando como trabalhava, como interagia com seus colegas, com os leitores, com a empresa em geral. "Quando terminei essa jornada, mais tremia de medo do que de entusiasmo. Estava bastante claro pra mim que o cargo exigia, além de competência e experiência profissional, muita resiliência e, principalmente, coragem" (ALMEIDA, 2019). 
Caio Túlio Costa citaria Magda posteriormente no livro que escreveu a respeito dessa sua experiência como ombudsman, com o subtítulo $O$ relógio de Pascal. No livro, ele afirma que "até meados de 1991 existiam 73 ombusdmen de imprensa em todo o mundo" (COSTA, 2006, p. 32) e que aqui no Brasil, após dois anos da inauguração da função pela Folha de S. Paulo, existiam apenas duas outras experiências semelhantes: no jornal cearense $O$ Povo, e no carioca $O$ Dia.

$\mathrm{Na}$ obra, Túlio Costa analisa ainda aspectos éticos do Jornalismo no Brasil e mostra os vários equívocos da profissão que o cargo lhe permitiu detectar. Segundo avaliação de Magda, o livro do colega explica

[...] as razões do narcisismo extremado de alguns jornais brasileiros, investiga as relações complicadas da mídia com a pesquisa de opinião pública a seu respeito e discute o que chamou de 'destino sombrio' do jornalismo impresso no país. Leitura imperdível para quem gostaria de entender melhor esse templo sagrado chamado redação e seus implacáveis sacerdotes (ALMEIDA, 2019).

Magda Almeida conta que visitou ainda jornais em Brasília, Pernambuco e Rio Grande do Sul, redações que tentaram a experiência de ombudsman, mas dela acabaram desistindo, algumas em tempo recorde. "Como me disse um editor: 'É muita areia para o meu caminhão"”, conta (ALMEIDA, 2019). De volta ao Rio após sua peregrinação entre as redações, Magda convocou a redação para uma conversa.

Percebi que havia, num primeiro momento, mais expectativa em relação a essa nova função do que recusa, embora alguns tenham deixado claro que $O$ Dia não era a Folha de S. Paulo e que o cargo não era uma escolha racional. Passei dias ouvindo mais do que falando. Não era fácil, à época, e para aqueles editores, fazer um jornalismo de qualidade com as deficiências estruturais que enfrentavam. Eram muitas e absurdas, em alguns casos. Aquele sonho poderia se transformar num pesadelo, se eu mantivesse os mesmos protocolos dos jornais de outros países e até mesmo do jornal paulista (ALMEIDA, 2019).

Foi após essa conversa na redação que Magda procurou a alta direção da empresa e fez uma contraproposta, uma condição para que aceitasse aquele cargo: ela não faria a crítica externa, uma vez que não era algo que fizesse parte da cultura dos leitores do jornal.

O que eles queriam mesmo, segundo as pesquisas já realizadas e a opinião de seu departamento de marketing, era "muito sangue e muita mulher pelada". Portanto, eu só faria a crítica interna, com circulação restrita à redação e à alta direção. Também não criticaria matérias assinadas, para evitar que me acusassem de estar "perseguindo" este ou aquele repórter, uma acusação comum em outros jornais, até como autodefesa. Repeti para a cúpula da 
empresa o que havia ouvido de um editor: O Dia não era a Folha, portanto, os protocolos do cargo, por uma questão de justiça, teriam que ser outros no caso de $O$ Dia. Ainda que alguns torcessem o nariz para minhas alegações, prevaleceu o bom senso (ALMEIDA, 2019).

A atuação de Magda, então, teve esse diferencial, identificado por Caio Túlio Costa: "a ombudswoman de O Dia, Magda de Almeida, com o título de Editora de Controle de Qualidade, apesar de fazer críticas internas e atender os leitores, não tinha coluna pública - e o cargo sumiu em pouco tempo" (COSTA, 2006, p. 32).

Com foco em um trabalho interno, Magda começava sua rotina de trabalho lendo vários jornais por dia, acompanhando o noticiário de todos, comparando ("o que fosse comparável") com o que se fazia no Rio e no jornal $O$ Dia, ouvindo as queixas dos leitores de todos os segmentos (notadamente servidores públicos, aposentados e moradores dos subúrbios do Rio de Janeiro e da Baixada Fluminense), conversando com os autores das reportagens que mereceram sua crítica, ou elogios. "Enfim, ouvindo as razões de cada um, tentando fazer um meio de campo que evitasse conflitos de qualquer espécie”, conta (ALMEIDA, 2019).

Eu pisava em ovos, mas encarava tudo aquilo como uma missão, um propósito visível de educar para melhorar. Mas uma coisa me incomodava especialmente: minha presença não era necessária, mas se tornou obrigatória nas reuniões que a presidência do jornal fazia, uma vez por semana, com os editores. Em meu íntimo, eu não concordava com a maneira como essas reuniões eram conduzidas, achava que os editores que a ela compareciam não mereciam as críticas que recebiam de seu superior, muito menos os momentos humilhantes pelos quais passavam. Minha presença ali os incomodava, com certeza. Decidi não comparecer a algumas, o que foi considerado uma atitude "insolente" (ALMEIDA, 2019).

Depois dessas ausências e sem aviso prévio, Magda não foi chamada mais para esses encontros e, por terceiros, soube, em 1992, que o cargo de "ombudsman" de $O$ Dia estava extinto após dois anos de atividade.

Para a redação em geral, foi uma festa (o fim do cargo de ombudsman). Para mim, um alívio. Estava formalmente desempregada? Não, porque, mais uma vez, o Walter (de Mattos) continuou confiando em mim e recomendou: "Pense num grande projeto para o jornal a partir dessa experiência". E foi o que fiz. Não lamentei, não achei que os dois últimos anos foram etapas perdidas em minha carreira. Pelo contrário, muito aprendi, ainda que tenha sido este um aprendizado dolorido. Antigas amizades foram rompidas, incompreensões de toda ordem davam origem a estresses desnecessários, enfrentei boicotes inimagináveis, a rádio corredor foi implacável, injusta, cruel, mas tenho certeza que ali deixei uma semente. Me consolava ligando para o Caio (Tulio Costa), um ombro amigo durante uma boa temporada. E assim me redesenhei (ALMEIDA, 2019). 
Com a extinção do cargo em 1992, a crítica das edições passou a ser feita pelos editores executivos da publicação. Eles se revezavam, sendo mais frequente a crítica feita pelo editor executivo responsável pela primeira reunião de pauta, que ocorria então antes das 10h. Tal editor avaliava a edição publicada, apontando erros e acertos e cobrando conteúdos veiculados por concorrentes e que ficaram de fora das páginas de $O$ Dia. Tais críticas chegaram a ser publicadas na parte inferior da página 2 do jornal, mas tanto a ação interna quanto a ação publicada não receberam o nome de ombudsman.

Dessas críticas surgiu a ideia, implantada nos anos 2000, de as edições de $O$ Dia serem avaliadas por uma professora de Língua Portuguesa, que diariamente apontava falhas redacionais na publicação e tirava dúvidas de escrita de repórteres e editores ao longo do dia. No entanto, não se tratava mais de uma crítica de mídia, mas da garantia de edições sem erros de português e com reportagens bem escritas.

Encerrada a experiência como ombudswoman, Magda continuou em $O$ Dia e criou um - então pioneiro na imprensa carioca - canal de interatividade do jornal: o "Fale com O DIA, a ponte entre o jornal e seus leitores", sendo o nome do jornal grafado em caixa alta como indicava o manual de redação do matutino. A jornalista buscou inspiração no clássico slogan do jornal (O Dia, De Braços com o Povo).

Decidi mostrar que, apesar do apelo demagógico dessa campanha, O Dia era uma marca poderosa entre a população periférica, nada mais justo estar, realmente, mais próxima dela. A redação, para surpresa minha, não discordou de todo, mas as nossas relações ainda estavam azedas, por mais injusto que isso me parecesse. Mas eu ainda tinha amigos lá dentro e foi com eles que eu contei nos momentos mais cruciais dessa experiência. Foi um outro aprendizado. Descobri o quanto era forte essa ligação do jornal $O$ Dia com seus leitores. Criei um 0800 para facilitar os contatos, consegui que a redação autorizasse uma chamada permanente no expediente desse novo projeto, aumentei o número de meus funcionários para tornar possível um atendimento mais eficaz, criei um programa de visitas ao jornal para os leitores, através de sorteio, enfim, leitor e jornal tiveram a oportunidade de mostrar as suas respectivas caras (ALMEIDA, 2019).

O projeto "Fale com $O$ DIA", conta a jornalista, não foi menos trabalhoso nem menos estressante que o de ombudsman. Historicamente, leitores e jornalistas, a seu ver, nunca haviam se entendido porque também nunca tinham sido apresentados.

Ninguém ignora o excesso de egos capazes de implodir uma redação no Brasil. Não importa o tamanho da empresa e de seu prestígio no mercado. Criaram-se mitos em torno do jornalismo e dos jornalistas, trabalhar em jornal, em nossa cultura, transformou-se num meio de ascensão social e cultural, sonho de consumo de muitos, uma ponte para a fama, o sucesso, imaginem uma juventude suburbana (origem da grande maioria dos 


\begin{abstract}
jornalistas nas décadas passada) tendo a oportunidade de conviver com os ricos e famosos, sendo por eles aceitos, festejados etc. e tal? Onde guardar o ego a essa altura, como mantê-lo sob controle? Impossível para alguns. Em minhas andanças pelas três maiores redações do país não foram poucas as vezes em que ouvi colegas atendendo leitores com desprezo e, não raro, com um palavrão. Quando não os deixavam esperando na portaria horas a fio, até que estes desistiam, indignados, ainda que ambos viessem do mesmo meio social. Nunca tive a pretensão de mudar essa quase cultura, mas percebi que, através do Fale com O DIA, eu poderia mudar alguns paradigmas e tornar essa relação menos predatória (ALMEIDA, 2019).
\end{abstract}

De acordo com a jornalista, o fato de ela ter sido a ombudswoman da redação não ajudava no projeto de maior interatividade com os leitores. Ela conta que enfrentou, mais uma vez, boicotes pesados, como quando foi eleita, em "concurso" promovido por um chefe de reportagem, a um posto nada honroso nominado por um palavrão. Meses depois, em outro "concurso", a "perua do ano". Não faltaram bilhetes e até "desenhos obscenos" deixados em sua mesa. Mas à medida que alguns desses jornalistas ("arautos do atraso", como ela define) foram sendo substituídos por profissionais mais qualificados e de visão, os espaços do Fale com $O$ DIA foram aumentando e o serviço seguiu em frente com relativo sucesso, fazendo, no seu ver, que leitores e jornalistas passassem a se entender melhor.

De acordo com a jornalista, a ação de interatividade do jornal com os leitores no formato implantado por $O$ Dia foi uma iniciativa pioneira nas empresas de comunicação no Rio e mesmo no país como um todo. Magda ficou à frente do serviço até a criação, por ela, do Instituto Ary Carvalho, o braço educacional e social do jornal. Com essa nova atividade, a jornalista deixou o Fale Com o DIA, e a função passou a ser exercida por uma empresa terceirizada, não jornalística, que mudaria completamente o sentido do projeto, transformando-o num SAC convencional. Magda ficou à frente do instituto até a aposentadoria.

\title{
Considerações finais
}

Os 30 anos da primeira experiência de crítica diária de mídia no Brasil acontecem em momento peculiar de ataques contra os veículos nacionais de comunicação, ambiente de onde emergem ainda arroubos conservadores machistas, homofóbicos e antidemocráticos. Rememorar a experiência da primeira jornalista a atuar nessa função e identificá-la com o marcador de gênero "ombudswoman" cumpre o 
papel histórico de manter vivos na memória aqueles tempos de esperançosa redemocratização em que a salutar crítica ao jornalismo era entregue a jornalistas, fossem eles homens ou mulheres. Uma crítica, diga-se de passagem, que buscava a qualidade do Jornalismo e não sua desqualificação como serviço em prol da democracia.

Tal resgate contribui ainda para fortalecer a atividade de ombudsman no Brasil. Afinal, por aqui, vêm perdendo força, em função da atual conjuntura, os debates já bastante amadurecidos na imprensa europeia e norte-americana sobre a presença de conselhos formados por jornalistas e proprietários das empresas de jornalismo, além de representantes da comunidade de leitores e anunciantes. Forma de autorregulação midiática, tais conselhos de imprensa são considerados, atualmente, o sistema de responsabilização da mídia mais eficiente em prol de uma imprensa plural e democrática, tendo seu papel de certificadora de conteúdos potencializado neste momento de fake news e manipulação de informações.

As três décadas de ombudsman e de "ombudswoman" no Brasil indicam um caminho que pode levar a imprensa local a um amadurecimento que favoreça a implantação de conselhos de auto-regulamentação em território brasileiro. Como marca dessa data, a rememoração da criação do cargo de ombudsman ganha força quando se buscam as lembranças da rotina desses profissionais em redações que viviam um contexto comunicacional diferente do atual, mas que geraram frutos para as novas gerações de jornalistas, em uma ambiência atual de multitarefas que nascia lá atrás.

A rotina de desafios, pesquisa, e até hostilidade relembrada pela jornalista que foi a pioneira em crítica de mídia no país nos faz refletir também sobre os jogos de poder, as negociações, os tensionamentos que existem nas redações dos jornais e que, de certa forma, atravessam a produção de conteúdo jornalístico. Trinta anos depois do surgimento dessa função na imprensa brasileira, jornalistas ainda precisam ser muito críticos com o que está sendo produzido, nos registros factuais, e também no que está sendo construído de memória para o futuro. Nesse sistema de ações pelo bom jornalismo, em ações de crítica interna e externa, atendimento ao leitor, avaliação de conteúdo e do que foi produzido de sentido, cabe ainda, no atual momento, aos jornalistas a função de certificação, em tempos de fluxos de conteúdos das mais diversas origens nas redes sociais digitais.

Este artigo, além dessa reflexão final, busca ainda contribuir para a história da 
imprensa brasileira, ainda carente de estudos e pesquisas que esmiúcem todos os seus aspectos, como a experiência de homens e mulheres jornalistas que, ao longo desses anos, empunharam a bandeira da crítica diária da mídia em busca da manutenção e do aprimoramento de um jornalismo de qualidade.

\section{Referências}

ALMEIDA, Magda. Jornalismo ontem e hoje. Cadernos da Comunicação, série Estudos, n. 15. Rio de Janeiro: Prefeitura da Cidade do Rio de Janeiro, 2006. p 48-55. Disponível em:

http://www0.rio.rj.gov.br/arquivo/pdf/cadernos_comunicacao/estudos/estudos15.pdf. Acesso em: 26 nov. 2019.

BARBOSA, Marialva. Jornalismo e construção de uma memória para a sua história. In: BRAGANÇA, Aníbal; MOREIRA, Sonia Virgínia (org.). Comunicação, acontecimento e memória. São Paulo: Intercom, 2005. p. 102-111.

BARBOSA, Marialva. Jornalistas, "senhores da memória"?. In: CONGRESSO BRASILEIRO DE CIÊNCIAS DA COMUNICAÇÃO [IV Encontro dos Núcleos de Pesquisa da Intercom], 27., 2004, Porto Alegre. Anais [...]. São Paulo: Intercom, 2004. Disponível em:

http://www.portcom.intercom.org.br/pdfs/5281189434155472217413491799349447635 .pdf. Acesso em: 30 dez. 2019.

BAUER, Martin; GASKELL, George (org.). Pesquisa qualitativa com texto, imagem e som: um manual prático. Petrópolis: Vozes, 2002.

BRANCO, Poliani Castello. Anos 60 e 70: ditadura, bipartidarismos e biônicos. Câmara dos Deputados, Brasília, 6 out. 2002. Disponível em: https://www.camara.leg.br/noticias/21997-anos-60-e-70-ditadura-bipartidarismo-ebionicos/. Acesso em: 30 jun. 2020.

COSTA, Caio Tulio. Ombudsman - o relógio de Pascal. São Paulo: A Girafa, 2006. v. 1.

CURIOSIDADE: nome ‘ombudsman' da função é comum aos dois gêneros. São Paulo, Folha de S. Paulo, 01. Jan. 2018. Disponível em:

https://www1.folha.uol.com.br/ombudsman/2018/01/1789462-nome-da-funcao-ecomum-aos-dois-generos.shtml. Acesso em: 28 jan. 2019.

GIL, Antonio Carlos. Métodos e técnicas de pesquisa social. 5.ed. São Paulo: Atlas, 1999.

LEAL, Carlos Eduardo; SANDRONI; Cícero; BASTOS, Ana Flávia. DIA, O. Centro de Pesquisa e Documentação de História Contemporânea do Brasil (CPDOC), Fundação Getulio Vargas, 2009. Disponível em http://www.fgv.br/cpdoc/acervo/dicionarios/verbete-tematico/dia-o. Acesso em: 25 jul. 2019. 
MESQUITA, Mário. La médiation solitaire de l'ombudsman de presse, Louvain: Recherches em Communication, 1998.

MUSSE, Christina Ferraz; THOMÉ, Cláudia. Repórteres de telejornal: o perfil ditado pela Rede Globo em 50 anos de televisão. In: ENCONTRO NACIONAL DE PESQUISADORES EM JORNALISMO, 13., 2015, Campo Grande/MS. Anais [...]. Disponível em:

http://pesquisafacomufjf.files.wordpress.com/2013/06/sbpjor2015final_ssimo.pdf. Acesso em: 14 jul. 2017.

REIS, Marco Aurelio. A crônica de Léo Montenegro - um olhar sobre o Carnaval do subúrbio do Rio entre 1965 e 2003. 2010. Dissertação (Mestrado em Ciência da Literatura) - Faculdade de Letras, Universidade Federal do Rio de Janeiro, 2010. Disponível em: https://drive.google.com/file/d/1lxmAEI97UiefpicBu-zlQqd5gfjAES4/view. Acesso em: 30 jun. 2020.

REIS, Marco Aurelio. O subúrbio feito letra: o cotidiano da periferia em crônicas ácidas e carnavalizadas. 2015. Tese (doutorado) - Faculdade de Letras, Universidade Federal do Rio de Janeiro, Rio de Janeiro, 2015. Disponível em https://drive.google.com/file/d/1J-7v9nuM2blwMZYgNKyTpYCmqneL78hn/view. Acesso em: 30 jun. 2020.

SILVA, Juremir Machado da. 1964. Golpe midiático-civil-militar. 5. ed. Porto Alegre: Sulina, 2014.

Submetido em: 31.10.2019

Aprovado em: 26.01.2020 